\title{
Study and Construction on the Professional Talents Training Mode in the Transformation Development of the Local Universities
}

\author{
Dan Guo \\ College Of Computer \\ Tonghua Normal University \\ Jilin, China \\ E-mail: guodan_1978@163.com
}

\begin{abstract}
At present, our country's economy is in the period of transformation development, which drives many local universities to follow and hope to cultivate applied talents meeting the demand of the market economy. In the critical stage of the transformation, the traditional talents training mode has deviated from requirement of the time more and more, the university students' employment is difficult, at the same time the shortage of employ persons is appeared in some enterprises and institutions. Under this circumstance, the local universities must reconstruct the talents training mode, they should combine with the their local economic characteristics and consider various elements including culture concept, major setup, institutional system, organizational form, management mode and evaluation system etc., to form a new set of professional talents training system. According to investigation, several local universities have carried out the professional talents training mode, the effect has gradually emerged. The students' professional skills have improved and they have better scores than before in all kinds of competition. The employment rates of various major have risen. It is believed that the professional talents training mode will be accepted by more local universities and which can further speed up the pace of the local universities transformation development, promote the steady economic growth of our country.
\end{abstract}

Keywords-Transformation; Talents training mode; Professional: Local university

\section{INEVITABILITY OF LOCAL UNIVERSITIES TRANSFORMATION}

Because of the global economic influence, the economic situation of China society is in the period of comprehensive transformation. The economic mode is changing from the extensive style to the intensive way, and the society structure is transiting from the difference to the combination between urban and rural areas. Such reforms must require the talents training to go with it and change, which made higher education especially including local universities face new challenges.

The structural unemployment problem of our country is more and more severe, which seriously influences country's macro-economy. On the one hand, it occurs the difficult situation that the technical talents who are hard to get high salary in the east of China, which called "labor shortage". On the other hand, it appears that the wages are falling and the students are unemployed for all kinds of higher universities, which called "great employment pressure". These circumstances explain that the talents training mode of high universities are already broken away from economic industrial structure, and its speed is also falling behind the developing steps.

From the view of our higher education's developing reform passing the several decades, the education needs change from inchoate elite education to popular education; the colleges' and universities' training center needs convert from advanced academic talents to applied talents by the employment and entrepreneurship guide.

\section{Connotation of PROFESSiOnal TALENTS Training MODE}

"Talents training mode" [1] is designed by the training body under the guarantee of the certain educational idea guidance and cultivation system to achieve the given talents training target. The mode's position needs consider some factors such as major establishment, course structure, teaching method, teaching system and so on. The talents training mode not only has generality but also has particularity.

Professional talents training mode is one of training modes, which pays attention to the idea of students oriented, keeps a foothold to enhance students' professional capacity, promotes the students' personalized development. The developing kernel of professional capacity is to create spirit development, and to create space and condition for the students' professional development. It helps students to optimize own professional quality, thereby it makes students definite innovative orientation and strengthen entrepreneurship ability.

\section{CONSTRUCtion OF Professional TALENTS Training MODE[2]}

Under the background of transformation development in local universities, the construction of professional talents training mode needs think about culture concept, major setup, institutional system, organizational form, management mode and evaluation system etc., such as Fig.1

The Twelfth Five-Year Plan Project of Jilin Education Science (GH150459) 


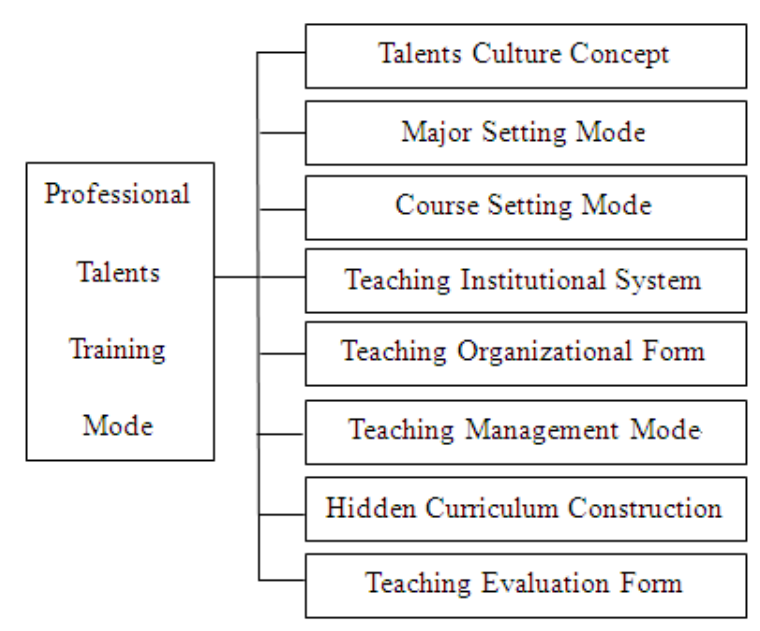

Fig. 1. Professional talents training mode

\section{A. Talents culture concept}

The talents culture concept plays an important controlling and guiding role for the construction of professional talents training mode, only the scientific concept of the talents cultivation is be established, the reasonable training target can be formed and the perfect talents training mode can be built. The local universities should combine own positioning with characteristics, recognize advantages and disadvantages, reference properly development experience of local universities at home and abroad, think over and condense to form own professional personal training concept. We also should observe students' features and professional abilities, to design scientific talents training mode. Such as agricultural universities, which obviously have the subject and major features in agriculture, so they should build agricultural professional talents training mode industriously, give consideration to professional and applied educational concept, bring up the students not only to work in scientific research institutions, upper agricultural management and technology promotion, but also to walk into rural grass-roots.

\section{B. Major setting mode}

The major setting mode is more traditional in our many colleges and universities, but it doesn't be totally repudiated, it should be further improved combining with current economic development situation. In the time of major setting, we don't request eagerly the new students to select their profession, and we should postpone properly the major selection, let students adapt the study and life in the university and exert their interests and potentials in the adequate time, later permit them to select profession. In the space of major setting, the local universities should give the students the chance of trying and changing. For example, we could allow students to study by changing or crossing the class, provide more conditions for the students' professional capacity development by making full use of the high quality education resources. In the caliber of major setting, in addition to improve continuously the current professional caliber, we also can draw lessons from foreign universities to encourage students to select widely the courses especially the crossing subjects, and extend the students' professional application by basing on the major setting of the thick foundation and wide caliber.

\section{Course setting mode}

First, adjusting course structure. One way is to improve the general course in the curriculum structure proportion. In addition to the common courses such as English, PE and morality, we should add the humanities ratio. Another way is to reduce the required course proportion and increase the optional course proportion. If the required courses are many, that will add the students' study burden. On the contrary, establishing some optional courses will give students study freedom and foster students' initiative. Second, optimizing course content. The main target of optimizing course content is to improve the students' creativity. One way is greatly improving the quality of the curriculum. The local universities should attach more importance to the construction of the curriculum at the university level, put forward reasonable constructing goals and abandon the idea that the curriculum is the ornament and supplement for specialized courses. Another way is improving the quality of the specialized courses. We should further strengthen the depth and frontier of the branch course and pay attention to the enlightenment of the subject research thinking and methods.

\section{Teaching institutional system}

First, perfecting credit system. We should break the traditional selecting courses system separated by the college and the department; change the unreasonable credit allocation, to make the credit of the required course and the optional course properly. Second, perfecting tutor system. We should set up the tutor committee in university and the tutor working team in college, let them take charge of own works such as the top deployment of the tutor system, the supervision of the tutors' working, the communication and the feedback of the tutors' opinions and suggestion. At the same time, we need set up the tutors' incentive and evaluating system. Third, perfecting scientific research system. Combining with the tutor system and the course setting, the local universities should accept the students to participate in the project with the tutor or increase the research-based teaching and discussion content, the students should submit research paper or report by the teachers' guidance. At the same time, the local universities should give the students financial support and enlarge degree of guidance. Fourth, perfecting academic visiting system. Considering from their respective situation, the local universities should find more foreign and domestic cooperating colleges and universities to provide the students more academic visiting chances, which can make the students go into some institutes or laboratories of the foreign and domestic first-class universities and take part in the high level of academic conferences. Similarly, the financial support is indispensable, which can avoid that the problem of "money" will be the barrier in the academic visiting way. Fifth, reforming practice system. We should adopt the practice form combined concentration with dispersion, link theory with practice, let students go deep into the production and practice line, and improve their practice capacity. 


\section{E. Teaching organizational form}

Based on the single class teaching, we should effort to expand the course scale and raise the course quality. The teaching activity is easily carried out in single class; the teachers implement various teaching activities by guidance and demonstration, such as heuristic teaching, inquiry teaching and project-driven teaching etc. In order to highlight the subject status of the students, the teachers' explanation and demonstration is indispensable, but their purpose is to guide and demonstrate, so the teachers' activity can't take the place of the students' independent thinking and action operation. Such teaching organizational form can make students think independently and practice actively, let them grasp specialized knowledge really, and which will turn into own inner quality.

\section{F. Teaching management mode}

In the aspect of the management ideology, we should build a student-based teaching idea[3]. For the specific teaching management transaction, the college is the main body who can accurately observe and analyze the teaching current situation, so the university should give the college higher teaching management right and made the college complete the teaching reform tasks effectively. For the students' own right, the college should give them the rights of participation and selection, let them take part in the college's varies teaching management activities. The college will listen to the students' opinion and make the teaching management achieve humanized reform. At the same time, the college should guarantee the students' rights of study and freedom, under the guidance of the university and the teachers, the students will freely select specialty, courses and teachers and so on.

\section{G. Hidden curriculum construction}

Setting up a rich and colorful hidden curriculum is an important measure to increase the students' individuality and harmonious development. According to own university's features, we should pay attention to combine the curricular with extra-curricular education form, and put forward the scheme and plan of hidden curriculum construction. Aiming to the excellent campus culture especially put education on the first place of the university working, we need build the studentbased and teacher-first campus culture. The curricular life also has the hidden curriculum, such as interaction between teachers and students in the tutor system. If the students get the praise and encouragement from the university and the teachers, they will play their subjectivity.

\section{H. Teaching evaluation form}

The teaching evaluation form being appropriate or not will influence the effect of the teachers' teaching and the students' study. In the process of the teaching evaluation, we should reduce the dependence on the exam scores and attach importance to the investigation of the students' practice and creative ability. No matter theory course or practice training, we should place extra emphasis on solving practical problems by applying the theory knowledge. When weighing the comprehensive performance, we won't simply calculate the normal score, mid-term score and final grade in every semester, we also will consider other elements such as the communication situation with tutor, the research circumstance after class and the development of non-intelligence factors. So, we can investigate and analyze the students' advantages and disadvantages versatilely.

\section{CONCLUSION}

Facing the situation of the transformation development in our country's local colleges and universities, some universities have transformed successfully, who implemented the professional or applied talents training mode, but the former was more. As the object of the talents training mode, the students have a high degree of satisfaction in teaching and learning. Their professional skills have improved and their learning enthusiasm has inspired, they got better score than before in all kinds of competition and the team cooperation ability has strengthened. Especially, the graduate employment situation has been improved, the employment rate has increased and employer has alleviated the problem of the staff shortage.

Certainly, the process of the local university transformation development is difficult, and the professional talents training mode is continuing to study and grope. This paper brings up some strategy, gives some local universities a little reference, and hopes to help the transformation development effectively.

\section{ACKNOWLEDGMENT}

This research was financially supported by the Twelfth Five-Year Plan Project of Jilin Education Science (GH150459).

\section{REFERENCES}

[1] Zefang Dong. "Concept Definition and Factor Analysis of the Talent Training Mode in Higher University". University Education Science. China, pp. 85-87, March 2012.

[2] Zhiyun Liu. "Creative Talents' Training Objective, Training Mode and Implementation Key". China University Teaching. China, pp. 144-146, January 2011.

[3] Zhen Qin. "Build Student-Based Teaching Idea to Increase Teaching Effect”. New Course Forum.China, pp169-171, December 2012. 